\title{
Modified clay composites as potential landfill covering material
}

\author{
JURIS BURLAKOVS ${ }^{1}$, MAIT KRIIPSALU ${ }^{2}$, AMIT \\ BHATNAGAR ${ }^{3}$, LiNDA ANSONE-BERTINA ${ }^{1}$, RUTA OZOLA- \\ DAVIDANE $^{1}$, MARIS KLAVINS ${ }^{1}$ \\ ${ }^{1}$ Faculty of Geography and Earth Sciences, University of \\ Latvia, Rainis Blvd. 19, Riga, LV-1586, Latvia; e-mail: \\ juris.burlakovs@lu.lv \\ ${ }^{2}$ Chair of Rural Building and Water Management, Estonian \\ University of Life Sciences, Kreutzwaldi 5, Tartu, 51006, \\ Estonia \\ ${ }^{3}$ Department of Environmental and Biological Sciences, \\ University of Eastern Finland, P.O.Box 1627, Kuopio, \\ FI-70211, Finland
}

Soil and groundwater may be contaminated with various pollutants due to the influence of leachate from closed dumps and landfills. It poses significant risks to the environment and human health. Contamination of soil and water can be minimized through sustainable landfill closure planning and process management. Modified clay composites may be used as constituents for building the landfill covering material and serving as easily manageable additive materials in order to reduce leaching effects. E.g., humic substances are the main component of soil organic matter - it actively interacts with pollutants $[1 ; 2]$. Humic acid-clay mineral composite materials would be prospective and low-cost sorbents for contaminant stabilisation. They might be considered for landfill closure projects as valuable constituents in the production of covering material in a mix with reworked fine fraction of waste and natural soil [3;4] as 1) Clay minerals effectively add humic substances; 2) Clay-humic composites are relevant for reduction of both organic and inorganic pollutants; 3) Sorption capacities increase, and there is low risk of toxic byproducts from the landfill covering material itself; 4) Clay-humic composites mixed with other landfill cover constituents would trap toxic contaminants (e.g., pharmaceuticals) found in reworked fine fraction of waste.

This study was supported by Project 1.1.1.2/VIAA/3/19/531 "Innovative technologies for stabilization of landfills - diminishing of environmental impact and resources potential in frames of circular economy".

[1] Awad et al. (2019) Sep Purif Technol 228, 115719 [2] Obaje et al. (2013) Int J Sci Technol 3, 264-270. [3] Chotzen et al. (2016) Clay Clay Miner 64, 628-638. [4] Burlakovs et al. (2017) Resour Conserv Recy 123, 73-84. 